\title{
Sleep deprivation and naps
}

\author{
DIANA R. HASLAM \\ Army Personnel Research Establishment, Farnborough, England
}

\begin{abstract}
It is important for military commanders to know the likely effects of a small amount of sleep under conditions of sustained operations. To this end, two laboratory-based experiments on naps were carried out. The first examined the effect of $2 \mathrm{~h}$ of sleep following $90 \mathrm{~h}$ of wakefulness. Ten infantrymen subjects were not told the scheduled length of their vigil, or that they would be allowed a nap at some stage, until a few hours before the 2-h nap. After 3 nights without sleep, the subjects' average cognitive performance was $55 \%$ of the control values. During a test session immediately before the 2 -h nap, performance improved by $30 \%$, to $85 \%$ of control values, indicating the considerable effect that the incentive of knowing that a nap is imminent can have on even severely sleep-deprived subjects. In the second experiment, two groups, each of six infantrymen, took part in a 5-day trial; for one group, $4 \mathrm{~h}$ of uninterrupted sleep was scheduled and for the other, four 1-h naps in each $24-\mathrm{h}$ period. There were no significant differences in cognitive test scores or mood between the two groups. On the last experimental day, cognitive test and mood scores were not significantly different from baseline values for either group, indicating the utility of $4 \mathrm{~h}$ of sleep, either in one uninterrupted block or in four scheduled 1-h naps per $24 \mathrm{~h}$.
\end{abstract}

\section{EXPERIMENT 1}

Under conditions of sustained military operations, it is important for commanders to know the least amount of sleep likely to be beneficial to their men after 2 or more days without sleep. In recent years, there have been a number of studies concerned with nap sleep, but most have examined the effect of fragmented sleep without initial sleep loss (Carskadon \& Dement, 1975; Moses, Hord, Lubin, Johnson, \& Naitoh, 1975; Webb \& Agnew, 1965; Weitzman, Nogeire, Perlow, Fukushima, Sassin, McGregor, Gallagher, \& Hellman, 1974; Wilkinson, Edwards, \& Haines, 1966).

Naitoh (1981), however, in a laboratory experiment, examined the effect, after $45 \mathrm{~h}$ of wakefulness, of $2 \mathrm{~h}$ of sleep in the early morning (from 0400 to $0600 \mathrm{~h}$ ) and, after $53 \mathrm{~h}$ of wakefulness, of $2 \mathrm{~h}$ of sleep at midday. Naitoh reported that the early morning nap resulted in severe and prolonged sleep inertia, and did not have any recuperative power, whereas the midday nap produced a relatively short sleep inertia and had clear recuperative power. Naitoh concluded that the recuperative power of a nap depended not only on its duration, but also, and more importantly, on the hours of prior wakefulness and the time of day when the nap was taken.

In a field study, Opstad, Ekanger, Nummestad, \& Raabe (1978) found, on the other hand, an improvement in the performance of cadets after either $3 \mathrm{~h}$ of sleep (from 0300 to $0600 \mathrm{~h}$ ) or $6 \mathrm{~h}$ of sleep (from 0001 to $0600 \mathrm{~h}$ ) occurring halfway through a combat training course lasting either 90 or $114 \mathrm{~h}$. In addition, $4 \mathrm{~h}$ of sleep in the early morning hours at the end of the course had a benefi-

The author's mailing address is: Army Personnel Research Establishment, Farnborough, Hampshire GU14 6TD, England. cial effect on test performance. In another field study, Haslam (1982) found that after $90 \mathrm{~h}$ without scheduled sleep, $4 \mathrm{~h}$ of sleep in the early morning hours (from 0145 to $0545 \mathrm{~h}$ ) had a marked beneficial effect upon the military performance and mood of 10 infantry soldiers.

Since both Haslam (1982) and Opstad et al. (1978) had found 4 and $3 \mathrm{~h}$ of sleep, respectively, to have a beneficial effect after prolonged wakefulness, and in view of Naitoh's (1981) negative finding, it was decided to examine further the value of nap sleep in the early morning hours following 3 to 4 days of wakefulness. As part of a larger study, it was decided to examine the effect of $2 \mathrm{~h}$ of sleep following $90 \mathrm{~h}$ without scheduled sleep. In order to simulate a military situation in which there was a foreseen lull in operation, subjects were told a few hours before the end of the vigil that they were going to be allowed some sleep. Up to this time, they had been ignorant of the scheduled length of sleep deprivation.

\section{Method}

\section{Subjects}

Ten trained infantrymen, members of the Army Personnel Research Establishment Trials Section, were the subjects. ${ }^{1}$ All were fit, none was taking medication, and no subject had previously taken part in a sleep-deprivation experiment. They were told that they were to be sleepdeprived for several days. If any subject felt unable to continue, he could report this to a medical officer. The subjects were divided into two groups of five, with one noncommissioned officer and four private soldiers in each group. In order to increase motivation, subjects were promised extra leave if they maintained a certain performance level in key tasks in relation to initial control (baseline) values. The group that showed least deterioration 
over the sleep-deprivation days was promised an additional day's leave. The data from the two groups were combined for statistical analysis. The average age of the total was 23.1 years, range 20 to 31 .

\section{Trial Design}

For the purposes of counting hours without sleep, the experiment started at $0630 \mathrm{~h}$, because this was the hour at which the subjects were awakened following the nights when $7 \mathrm{~h}$ of sleep was scheduled. However, the experimental days (Days E1, E2, etc) ran from midnight to midnight, because this is normally thought of as a $24-\mathrm{h}$ period. During the first 33/4 days (Days E1 to E3, 89.75 h), there was no scheduled sleep. Subjects were not told the intended length of the sleep-deprivation period until a few hours before their first allocated sleep. The sleep-deprivation period was preceded and followed by a 2-day control period. Seven hours of uninterrupted sleep (from 2330 to $0630 \mathrm{~h}$ ) in each $24 \mathrm{~h}$ was scheduled for the nights before the control days. The first of the control days was preceded by 1 day of training, and the second by $1 \frac{118 \text { days }}{10}$ ( $27 \mathrm{~h}$ ) of rest and sleep (Table 1). At the 89-h-awake point (2330 h on Day E3), the sequence of events shown in Table 2 was made known to the subjects. For both sleep periods, subjects remained fully dressed in combat kit (less boots) and slept on camp beds in a lightproof laboratory free from noise. From 0830 , subjects were allowed to sleep until they awoke spontaneously.

During the week preceding the trial, the subjects underwent training on the performance tests to minimize practice effects over the trial period. Throughout the trial, subjects were observed by military, civilian, and medical staff for $24 \mathrm{~h}$ a day. One of the duties of this staff was to ensure that subjects had no unscheduled sleep. They did this by tapping a subject on the shoulder and telling him to awaken as soon as he appeared to doze.

\section{Pattern of Activities}

During the trial period, subjects ate and slept in the laboratory, and a program of tests and activities was devised to keep them occupied for most of the day, as well the night during the sleep-deprivation period. The activities included military tasks like paper-and-pencil map- reading tests, transcribing (copying) military statements, and detecting vehicles on a TV monitor. In addition, weapon-handling tests were carried out daily, and subjects marched for 1.5 miles twice daily. In order to relieve the monotony inherent in a trial of this nature, subjects were taken each evening to a small-bore shooting range. With regard to individual performance assessment, only the tests that were given before and after the $2 \mathrm{~h}$ of sleep $(0015$ to $0215 \mathrm{~h})$ are described here.

\section{Encoding/Decoding Tests Using Military Ciphers}

Encoding and decoding tests (Dudley, Huband, Hartley, \& Brown, 1972; Haslam, 1982; Haslam, Allnutt, Worsley, Dunn, Abraham, Few, Labuc, \& Lawrence, 1977) provide an indication of cognitive ability and are susceptible to sleep-loss effects. A product-moment correlation of 0.6 for 12 subjects (unpublished data) has been found between performance on encoding/decoding grid references and performance on the Stroop test. The encoding/decoding tests are fairly complex, and accurate performance requires sustained attention. In addition, these tests are relevant and meaningful to the Army and are assumed to be motivating. (For military security reasons, details cannot be given.)

\section{Encoding/Decoding Grid References (Mapco)}

Subjects were given $5 \mathrm{~min}$ for encoding, followed by $5 \mathrm{~min}$ for decoding. The test consisted of 30 six-figure grid references and 30 five-letter codes (e.g., EDJGA) that had to be encoded and decoded, respectively, using a code strip printed across the top of the page. Performance was scored for the number of correct answers and the number of errors. Experimental day test sessions were given at 1000 and $0230 \mathrm{~h}$. During the control days, there was one session daily (at $1000 \mathrm{~h}$ ) because of the subjects' sleep schedule. Due to circadian effects, performance would be expected to be better at $1000 \mathrm{~h}$ than at $0230 \mathrm{~h}$.

\section{Decoding Messages (Slidex)}

In this 10-min test, which always followed the Mapco test, a message was decoded from a collection of bigrams (e.g., AB LM BY, etc). A Slidex card and a different cur-

Table 1

Trial Design

\begin{tabular}{|c|c|c|c|c|}
\hline Day 1 & Days 2 and 3 & Days 4 to 7 & Day 7 & Days 8 and 9 \\
\hline $\mathrm{T} 1$ & $\mathrm{C} 1, \mathrm{C} 2$ & $\mathrm{E} 1$ to $\mathrm{E} 4$ & $\mathrm{R} 1$ & $\mathrm{C} 3, \mathrm{C} 4$ \\
\hline $\begin{array}{l}\text { Training on } \\
\text { all tests } \\
\text { and pro- } \\
\text { cedures. }\end{array}$ & $\begin{array}{l}\text { Control: } 7 / 24 \mathrm{~h} \\
\text { of sleep pre- } \\
\text { ceding } \mathrm{C} 1, \mathrm{C} 2 . \\
\text { Testing at } 1000 \mathrm{~h} \text {. }\end{array}$ & $\begin{array}{l}\text { Experimental: No } \\
\text { scheduled sleep on } \\
\text { Days E1 to E3. } \\
\text { Testing on Days E1 } \\
\text { to E3 at } 0230 \mathrm{~h} \text { and } \\
1000 \mathrm{~h} \text {, followed by } \\
\text { test/nap/test period } \\
\text { (detailed in text and } \\
\text { Table 2). }\end{array}$ & $\begin{array}{l}\text { Rest/sleep: } \\
27 \mathrm{~h} .\end{array}$ & $\begin{array}{l}\text { Control: } 7 / 24 \mathrm{~h} \\
\text { of sleep. Testing } \\
\text { at } 1000 \mathrm{~h} \text {. }\end{array}$ \\
\hline
\end{tabular}


Table 2

Sequence of Events at the 89-h Awake Point

\begin{tabular}{|c|c|c|c|c|}
\hline \multicolumn{5}{|c|}{ Hours } \\
\hline $2330-0010$ & 0015-0215 & $0215-0245$ & 0245-0330 & 0330- \\
\hline $\begin{array}{l}\text { Cognitive } \\
\text { test } \\
\text { session }\end{array}$ & Sleep & $\begin{array}{l}\text { Interval } \\
\text { to permit } \\
\text { awakening }\end{array}$ & $\begin{array}{l}\text { Cognitive } \\
\text { test } \\
\text { session }\end{array}$ & $\begin{array}{l}\text { Unlimited } \\
\text { sleep }\end{array}$ \\
\hline
\end{tabular}

sor setting were used at each test session. Performance was scored for the number of bigrams correctly decoded and for the number of errors.

\section{Statistical Analysis}

The data were analyzed by means of a mixed-model Type 3 ANOVA, and a priori contrasts were used to compare performance on different days, performance at different times of day, and the anticipation and "effect" of the 2-h sleep period.

\section{Results and Discussion}

All 10 subjects completed the trial. No subject had more than a few seconds at a time of unscheduled sleep, and the total amount taken was small, due to the constant intervention of the observers.

\section{General Behavior}

On the third day of sleep loss, subjects were continually dozing off, especially diring the cognitive test session at $1000 \mathrm{~h}$, but they were awakened immediately by observers. Also, during the afternoon on the 3rd day of sleep loss, subjects appeared to be in a daze when they went from one laboratory to another for the various test sessions; during the relaxation period, they could not maintain concentration on a card game for more than a few seconds at a time. During the last few hours of the vigil, when they knew the 2-h sleep period, and the end of the experiment, were in sight, the subjects appeared to be cheerful and alert, and did not have the appearance expected of people who had been awake for almost $90 \mathrm{~h}$.

\section{Recovery Period}

The average amount of sleep taken when the subjects were allowed unlimited sleep at the end of the deprivation period was $9.7 \mathrm{~h}$, range 7.5 to 11.3 . This, together with the $2 \mathrm{~h}$ they were allowed before the last test session, amounts to an average of $11.7 \mathrm{~h}$.

\section{Objective Tests}

Encoding and decoding grid references (Mapco). The results can be seen in Figures 1 and 2. The analysis of variance showed the between-sessions variable to be sig-

\section{Encoding grid references (MAPCO)}

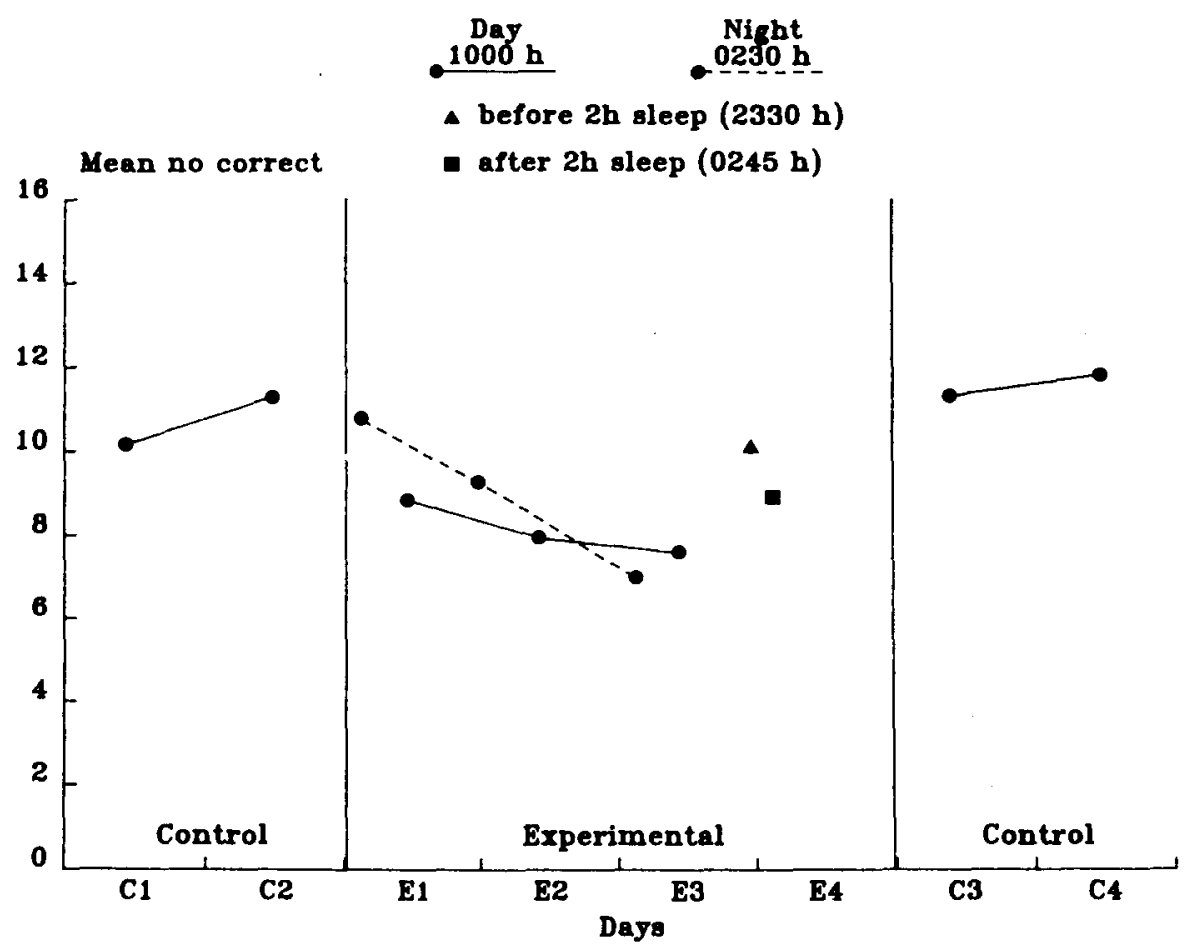

Figure 1. The effect of sleep loss upon Mapco encoding performance at different times of day. The triangle and square denote performance before and after $2 \mathrm{~h}$ of sleep at the end of a 90 -h vigil. Average scores for 10 subjects. 


\section{Decoding grid references (MAPCO)}

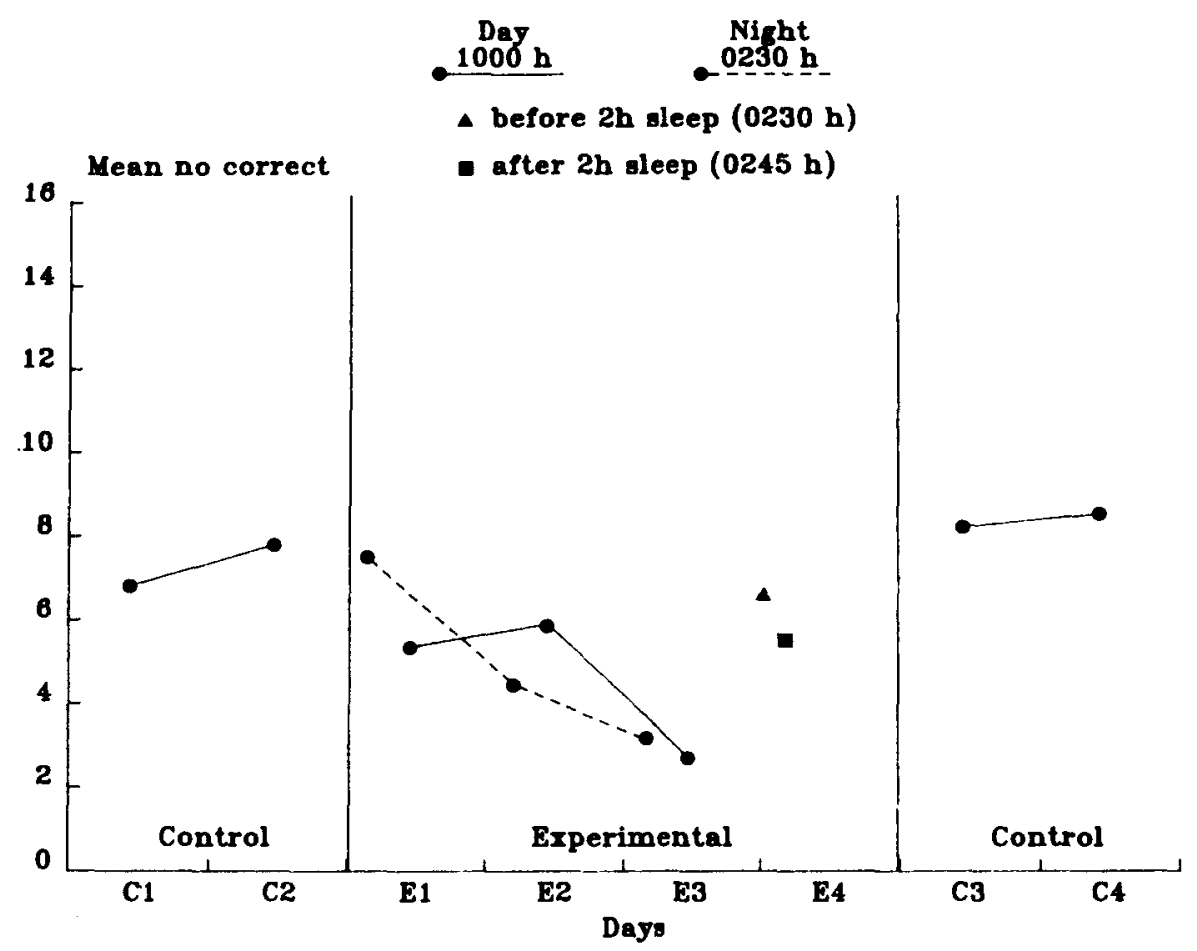

Figure 2. The effect of sleep loss upon Mapco decoding performance at different times of day. The triangle and square denote performance before and after $2 \mathrm{~h}$ of sleep at the end of a $90-\mathrm{h}$ vigil. Average scores for 10 subjects.

nificantly different at the $\mathrm{p}<.001$ level $[\mathrm{F}(11,99)=2.63$ for encoding, 6.06 for decoding]. There were no statistically significant differences between day $(1000 \mathrm{~h})$ and night $(0230 \mathrm{~h})$ scores during the sleep-deprivation phase and no difference between 1000-h scores on Days $\mathrm{C} 1$, $\mathrm{C} 2$ and Days C3, C4. However, the number of items correctly completed dropped over the sleep-deprivation days. This was due mainly to a drop in the number of items attempted from Day E1 to Day E3 and not to an increase in errors, a finding much like that reported by Thorne, Genser, Sing, and Hegge (1983).

Further analysis using selected contrasts indicated that performance on Day E3 at $1000 \mathrm{~h}$ was significantly worse than on Days C1, C2, and on Days C3, C4. However, performance at $2330 \mathrm{~h}$ before the $2 \mathrm{~h}$ of sleep (Day E3) was significantly better in the decoding test (Figure 2) than at $1000 \mathrm{~h}$ on Day E3 ( $p<.001$ ), and although there was an improvement in encoding, a difference of $33.8 \%$ (Figure 1), it was not statistically significant. There was no significant difference between day and night scores.

Decoding messages (Slidex). The results can be seen in Figure 3. The analysis of variance showed sessions to be significantly different at the $p<.001$ level $[F(11,99)$ $=4.32]$. During the sleep-deprivation period, subjects were slower than during the control periods: The number of items attempted decreased, but there was no statisti- cally significant change in the number of errors. The difference between day and night scores was not significant. Further analysis using selected contrast tests indicated that decoding performance on Day E3 at $1000 \mathrm{~h}$ was significantly worse than on Days C1, C2 and Days C3, $\mathrm{C} 4$. Compared with performance at $1000 \mathrm{~h}$ on Day E3, performance improved slightly before the $2 \mathrm{~h}$ of sleep, the difference being $28.6 \%$, not statistically significant.

Although scores on Days C3, C4 were not significantly better than those on Days $\mathrm{C} 1, \mathrm{C} 2$, there was a tendency in that direction, perhaps attributable to repeated test sessions. Unlike the results for the Mapco tests, there was a tendency for performance to be better after the sleep than before it; this could reflect the length of time since awakening.

Kleitman (1972) found that performance at $2330 \mathrm{~h}$ was approximately the same as performance at $1000 \mathrm{~h}$. However, in the experiment reported here, on Day E3, there had been 13.5 additional hours without sleep by $2330 \mathrm{~h}$, compared with $1000 \mathrm{~h}$ that day. Therefore, in the absence of incentive, it might be expected that performance would be worse than at $1000 \mathrm{~h}$. However, as indicated above, there was an improvement in all three tests. Although statistical significance was reached in only one of these (decoding grid references), it is clear that the anticipation of sleep had an effect. 


\section{Decoding messages (SLIDEX)}

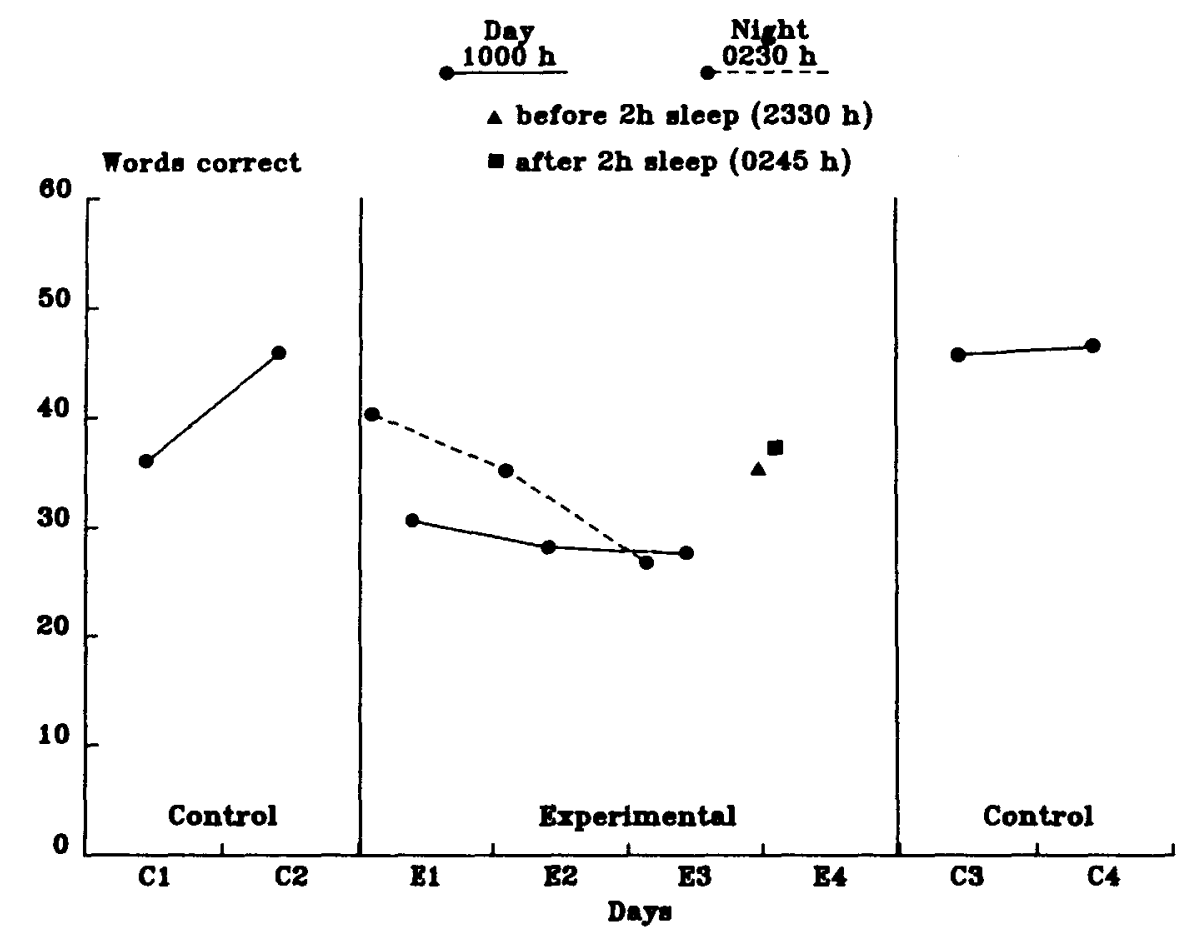

Figure 3. The effect of sleep loss upon Slidex decoding performance at different times of day. The triangle and square denote performance before and after $2 \mathrm{~h}$ of sleep at the end of a 90-h vigil. Average scores for 10 subjects.

If it had not been shown that performance had improved by $30 \%$ before the 2 -h sleep period, it would have seemed that this 2 -h nap had improved performance by $22 \%$ (it is unlikely that any incentive effect would have outlasted the sleep). However, because of the apparent effect of the anticipation of sleep on performance, conclusions to be drawn about the value of the $2 \mathrm{~h}$ of sleep per se are complicated. Subjects knew they were going to be allowed unlimited sleep following the test session, and anticipation of this may well have affected their performance.

The effect of incentive improved performance by $30 \%$, but the tests were only of 5-and 10-min duration. Nonetheless, these were the tests that were adversely affected over Day E1 to Day E3. The effect on a task of greater length, and the duration of time over which such mental stimulation would be effective, is unknown at present, but these are questions that will be addressed.

We did not know the extent of cognitive improvement possible in severely sleep-deprived individuals. The finding that average performance for the three tests improved before the $2 \mathrm{~h}$ of sleep from $55 \%$ of control values to $85 \%$ of control values brings to mind the statement by Whiting and English (1925) that fatigue does not directly cause work decrement but raises the threshold at which work motives are effective. They went on to say that "if such positive motives are adequate at all, then fatigue has no effect upon work efficiency" (p. 49). If this statement is true, it raises the question of the function of sleep. As Horne (1981) said, "If much of human sleep were for cerebral restitution, then the extent of cerebral capacity to perform at near optimal levels during limited total sleep deprivation would be less than is found" (p. 97). Even if the function of sleep is not apparent it seems unlikely that it is for body restitution (Horne, 1978). [More recently (1983), Horne indicated in a personal communication that sleep does have a restorative function.] The need to sleep after sleep loss seems to have the essential qualities of a physiological drive, which increases in relation to sleep deprivation (Akerstadt \& Gillberg, 1981; Dement, Seidel, \& Carskadon, 1982) and has the effect of decreasing the interest in, and motivation to carry out, other tasks. However, if sufficient incentive is injected into the situation, for example, by the promise of sleep, then the downward trend of performance can, on short tasks anyway, be reversed, demonstrating a reserve and manipulative mental capacity even in the presence of severe sleep deprivation.

\section{EXPERIMENT 2}

In sleep-deprivation research, the effects of total sleep loss have been studied to a greater extent than have the ef- 
fects of partial sleep loss. However, in recent years, there have been a number of studies of reduced or fragmented sleep and naps (Carskadon \& Dement, 1975; Hamilton, Wilkinson, \& Edwards, 1972; Haslam et al., 1977; Moses et al., 1975; Naitoh, 1981; Opstad et al., 1978; Taub, 1979; Taub \& Berger, 1976; Webb \& Agnew, 1965, 1974, 1977; Weitzman et al., 1974; Wilkinson et al., 1966).

Situations in which partial sleep loss is likely may be of several types: One such type may demand almost continuous cognitive work, such as that required, for example, of pilots, radar operators, and command and control center operators. Another type may demand a combination of physical and mental work, such as that required of the armed forces in combat or of civilian police forces and medical workers in emergency situations.

In a study of continuous cognitive work, Mullaney, Kripke, and Fleck (1981) examined performance over a $42-h$ period. They found that a group with $1-h$ naps at 6-h intervals and a group with one 6-h period of sleep after $18 \mathrm{~h}$ of continuous work performed better than a group who worked continuously without sleep. The 1-h rests were beneficial in the first $18 \mathrm{~h}$, but the 6 -h rest was better over the 42-h period. However, as Mullaney et al. pointed out, on the 2 nd day, the amount of rest taken by the 6-h sleep group exceeded that of the 1-h group, and, by the end of the experiment, the latter group had had 1-h less sleep than the former group.

In the experiment by Moses et al. (1975), $60 \mathrm{~min}$ of sleep were alternated with $160 \mathrm{~min}$ of testing over a $40-\mathrm{h}$ period. No impairment was found on six of the eight measures used, but as in the experiment by Mullaney et al. (1981), the duration of the experiment was relatively short.

The usual finding in sleep-deprivation studies is that cognitive performance deteriorates, whereas physical performance does not. In order to study the effects of sleep loss in the type of situation in which the infantryman may find himself, that is, a combination of mental and physical work, assessments were made of cognitive functioning and mood in the experiment reported here, which was of 100 -h duration. A militarily realistic schedule is a period of approximately $24 \mathrm{~h}$ without sleep, followed by several days with limited amounts of sleep. A question frequently asked by military personnel is whether one period of uninterrupted sleep is better than several naps. In an attempt to answer this question, the experimental plan was to give one group of subjects $4 \mathrm{~h}$ of uninterrupted sleep in every $24 \mathrm{~h}$ and the other group four 1-h naps at 6-h intervals. The greater duration of this experiment than that of Mullaney et al. (1981) made it possible to have one test session every $24 \mathrm{~h}$ when the two groups had the same amount of sleep.

On the basis of the results from an earlier experiment (Haslam, 1982), it was assumed that, following $23 \mathrm{~h}$ without sleep, $4 \mathrm{~h}$ of sleep would be sufficient to restore performance (if degraded) to baseline levels and to main- tain it there for the following 4 days. In the case of the 1-h nap sleep, it was thought that such a disruption of the sleep/wakefulness cycle would degrade performance in this group over the fragmented-sleep period and ultimately be worse than baseline levels. This would be in keeping with predictions by Taub and Berger (1973).

\section{Methods}

\section{Subjects}

Twelve trained infantrymen were allocated randomly to two groups of six, with one noncommissioned officer and five private soldiers in each group. The average age of Group A was 22.3 years (range 21 to 29), and that of Group B, 23.5 years (range 19 to 32 ).

In order to motivate the subjects, the two groups competed against each other; the competition was based on the maintenance of performance levels in the cognitive tests in relation to baseline values for the reward of an extra day's leave. The groups were not provided feedback on their performance during the experiment.

\section{Trials Design}

The experiment lasted from Monday (Day 1) to Friday (Day 5). On the Sunday night preceding the trial period, the subjects were scheduled $6 \mathrm{~h}$ of sleep. Group A's scheduled sleep was from 2100 to $0300 \mathrm{~h}$, and Group B's was from 0000 to $0600 \mathrm{~h}$. Sleep was scheduled at these times in order that both groups would have been without sleep for the same length of time, that is, $23 \mathrm{~h}$, when they were allowed their first $4 \mathrm{~h}$ of sleep or 1-h nap. After awakening, Group A played cards under supervision from 0300 to $0600 \mathrm{~h}$.

During the experimental period, Group A slept from 0200 to $0600 \mathrm{~h}$; Group B slept from 0500 to 0600,1100 to 1200,1700 to 1800 , and $2300 \mathrm{~h}$ to midnight. During the periods when one group was sleeping and the other was not, the latter group played TV games, an undemanding sedentary activity.

Subjects carried out a number of physical activities and cognitive tests in order for there to be a combination of continuous physical and mental work. The physical activities included two one-mile marchs [with each man carrying a 13.61-kg (30-lb) pack], rifle shooting, weapon training, negotiating an assault course, and simulated handcranking in a tank. These activities were carried out at the same time each day.

The subjects were observed by staff members, who ensured that the subjects had no unscheduled sleep. Before the trial began, subjects were briefed about their sleep schedules and the duration of the trial.

For the first two sessions (Day 1, $1000 \mathrm{~h}$; Day 2, $0100 \mathrm{~h}$ ), subjects were not sleep deprived to any great extent; data from these sessions therefore served as baseline (B) levels for comparison with results from tests at similar times of day on the succeeding days (Days E3, E4, and E5). On Days E3, E4, and E5, for the cognitive 
test session at $0100 \mathrm{~h}$, the two groups of subjects had the same amount of sleep; however, Group B had awakened from their nap $1 \mathrm{~h}$ previously.

\section{Cognitive Tests}

The duration of the cognitive test session was $1 \mathrm{~h}$. Three paper-and-pencil tests, sensitive to sleep deprivation, were used to assess cognitive functioning: a perceptual speed test (number cancellation), an addition test, and a logical reasoning test (adapted from Baddeley, 1968). Each test was of 15-min duration, with approximately a 1-min interval between tests.

The perceptual speed test consisted of sheets of numbers typed from tables of random numbers. Twenty-five rows of 30 digits were presented; the left-hand number of each row was circled. The task was to cross out every digit in the row that was the same as the one circled in that row. There was a total of 20 sheets of digits, 14 of which were presented in a random order on each occasion. The scores were the number of digits correctly marked in the time allowed, the number of digits missed (errors of omission), and the number of digits incorrectly marked (errors of commission).

The addition test consisted of two pages of 100 sums arranged in 10 rows of 10 sums. Each sum consisted of three two-digit numbers to be added. There were 10 different pages of sums, two of which were presented in a random order on each occasion. Performance was scored according to the number of correct additions and the number of errors.

The logical reasoning test is a test of "higher mental processes" (Baddeley, 1968) and has been used successfully in previous sleep-loss experiments (Haslam, 1982; Haslam et al., 1977; Thorne et al., 1983). The test consisted of 16 pages, each with 32 sentences of the following type: "A follows B," " B does not precede A." Each sentence is followed by the letters $\mathrm{AB}$ or $\mathrm{BA}$, and the subject is required to indicate, by putting a tick in a box, whether the sentences are a true or false description of the pairs of letters. The pages were presented in a random order. The number of correct responses and the number of errors were measured.

\section{Mood Questionnaire}

At the end of both cognitive test sessions, subjects completed the Profile of Mood States (POMS) (McNair, Lorr, \& Droppleman, 1971), a questionnaire in which the factors of tension, depression, anger, confusion, fatigue, and vigor are assessed. These can be summed, with vigor weighted negatively, to give a Total Mood Disturbance Score. The time taken to complete the questionnaire was approximately $6 \mathrm{~min}$.

In order to eliminate practice effects over the experimental period, during the week preceding the trial, the subjects underwent training sessions on the tests, and also on the mood questionnaire. Asymptotic performance was achieved on the tests.

\section{Sleep Logs}

In order to find out the subjective assessment of the amount of sleep taken, sleep lings were completed by the subjects for each period of scheduled sleep. The amount of self-reported sleep was found earlier to match closely the amount of EEG-recorded sleep (Haslam et al., 1977).

\section{Statistical Analysis}

Responses were investigated both within and between groups. For each group, a priori selected contrasts were planned to examine changes from the baseline for both day and night tests. For the experimental Days E2 to E5, a comparison between day and night test sessions was examined. The contrasts were:

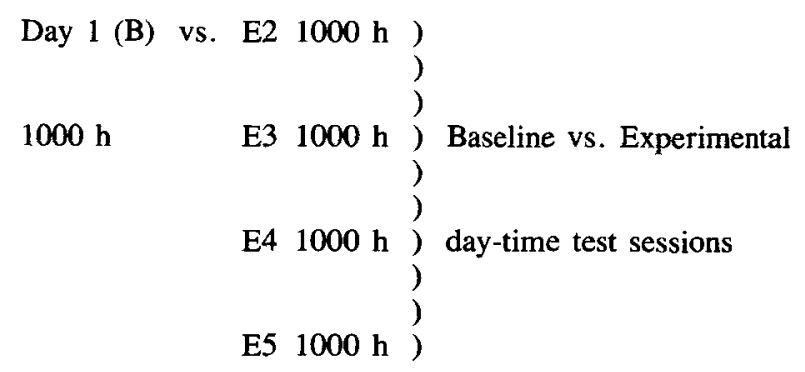

$\begin{array}{ll}\text { Day } 2(\mathrm{~B}) & \text { E3 } 0100 \mathrm{~h}) \text { Baseline vs. Experimental } \\ 0100 \mathrm{~h} & \text { E4 } 0100 \mathrm{~h} \text { ) night-time test sessions } \\ & \\ & \text { E5 } 0100 \mathrm{~h})\end{array}$

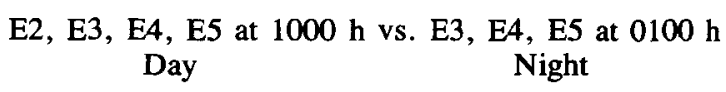

The analysis for comparing Groups A and B was a twofactor repeated measures design (Winer, 1971). The strategy for determining the appropriate degrees of freedom, when the usual assumptions about the form of the variance-covariance matrix may not hold, was that described in Greenhouse and Geisser (1959).

\section{Results and Discussion}

All 12 subjects completed the study. No unscheduled sleep was taken, and, in reply to questioning in a debriefing session, no one apparently felt the need for it.

\section{Scheduled Sleep}

On the Sunday night preceding the experiment, the average amount of sleep taken by Group $A$ was $4.4 \mathrm{~h}$ and by Group B $4.9 \mathrm{~h}$ ( $6 \mathrm{~h}$ was scheduled for both groups). The time of retiring $(2100 \mathrm{~h})$ of Group $A$ and the unfamiliarity of the surroundings probably contributed to the deficit. Because it had been established that $4 \mathrm{~h}$ of uninterrupted 
sleep in every $24 \mathrm{~h}$ is sufficient to maintain performance over several days (Dudley et al., 1972), the scores obtained on the 1st day were used as baseline measures.

The average amount of sleep taken over Days E2 to E4 was $3.83 \mathrm{~h}$ by Group A and $3.10 \mathrm{~h}$ by Group B. This difference was significant $(p=.004$, Mann-Whitney $U$ test).

From Day E2 to Day E4, the average total amount of sleep taken by Group A was $11.5 \mathrm{~h}$, and by Group B, $9.3 \mathrm{~h}$. The average total amount of sleep taken by Group A from the Sunday night to Day E4 was $15.9 \mathrm{~h}$, and by Group B, 14.2 h. Thus, the shortfall on Days E1 to E4 for Group B was partly offset by the greater amount of sleep they had on Sunday night. From Day E2 to Day E4, Group B had $2.2 \mathrm{~h}$ fewer hours of sleep than Group A. This was presumably due largely to the fact that for Group B there were four occasions in every $24 \mathrm{~h}$ in which to fall asleep. On the face of it, this would be an argument against scheduling nap sleep; however, since there was no significant difference in performance or mood between the two groups, perhaps it is an indication that several short periods of sleep are no less beneficial than one uninterrupted period of sleep.

\section{Performance on Cognitive Tests}

Analysis of variance indicated that there was no significant difference in Group A and Group B performance on any test. The groups did not behave differently from each other over time.

Scores for both cognitive test sessions (1000 and $0100 \mathrm{~h}$ ) were compared with baseline values, and, although there were some significant differences, there was no meaningful pattern in the results.

\section{Day Versus Night Over Experimental Days}

Group A. There were no significant differences in number correct between day and night performance for perceptual speed and arithmetic; logical reasoning performance was significantly better at night $[\mathrm{F}(1,11)=5.58$, $\mathrm{p}<.05]$.

Group B. In all three tests, night performance was significantly better than day performance [perceptual speed, $\mathrm{F}(1,9)=17.44, \mathrm{p}<.01$; arithmetic, $\mathrm{F}(1,15)=9.81$, $p<.01$; logical reasoning, $F(1,10)=6.99, p<.05]$.

It may be that Group B performed better at night because they recently had had some sleep, or because all subjects had, during the course of the evening, been swimming and been shooting in an indoor range. These activities may have had an arousing effect, but less so for Group A subjects because they were near the end of their period without sleep.

\section{Mood Questionnaire-POMS}

Analysis of variance indicated that there was no significant difference in mood between Groups $A$ and $B$, and that the group $\times$ sessions interaction was not significant. For both groups ( $A$ and $B$ ), the sessions main effect was significant for tension, fatigue, vigor, and total mood score; therefore, selected contrasts were made. At $1000 \mathrm{~h}$ on Days E2 to E4 mood was significantly worse than on the baseline day on all scales except depression and anger for Group A and depression for Group B. There were no significant differences over time for night scores for either Group A or Group B.

\section{Psychological Factors}

For both groups, if the results showed any pattern at all, it was one of slight deterioration in performance and mood in the middle of the trial, with recovery at the end.

Each test reported in the present study was of relatively short duration-15 min. However, the actual length of the cognitive test sessions was $1 \mathrm{~h}$, a period of work that is representative in a realistic situation in which several different tasks may be undertaken sequentially.

Longer tests have on occasion been used in partial-sleeploss studies, for example, 1-h vigilance and arithmetic tasks (Hamilton, et al., 1972; Wilkinson et al., 1966). But only Hartley (1974) appears to have compared the effects of uninterrupted versus nap sleep on such tasks. The Wilkinson et al. and Hamilton et al. experiments were of the continuous cognitive work type, referred to earlier in this report. Wilkinson et al. alternated 1-h sessions of arithmetic and vigilance over a 14.5-h day for 2 days, and Hamilton et al. alternated these tests (and included two .5-h memory tests) over an 8-h day for 4 days. After applying signal detection theory to his vigilance data, Wilkinson $(1969$, p. 41$)$ concluded that until the first $3 \mathrm{~h}$ of sleep were intruded upon, there was no change in the capacity, as opposed to the willingness, to perform the task. This statement is reminiscent of the work of Whiting and English (1925), who reported that fatigue does not directly cause work decrement but raises the threshold at which work motives are effective.

Sleep studies of the type reported here are, of necessity, repetitive, and they therefore tend to become monotonous to the subjects. During the middle of the trial, when there was least stimulation (because the experience was neither new nor nearly over), mood and performance deteriorated. On the last day, however, when morale was high, scores returned to baseline levels, suggesting that, during the middle of the experiment, the work motive, rather than efficiency, had been impaired.

\section{CONCLUSIONS}

(1) Nap sleep is as beneficial as a scheduled equivalent amount of uninterrupted sleep.

(2) Four hours of scheduled sleep, whether taken as naps or undivided, appears to be sufficient for these aspects of behavior following an initial $23 \mathrm{~h}$ of sleep deprivation.

\section{REFERENCES}

Akerstadt, T., \& GillberG, M. (1981). Sleep, stress and recuperation. In W. P. Koella (Ed.), Sleep 1980: Proceedings of the Fifth European Congress on Sleep Research (pp. 98-101). Basel: Karger. 
BADDELEY, A. D. (1968). A 3-minute reasoning test based on grammatical transformations. Psychonomic Science, 10, 341-342.

Carskadon, M. A., \& Dement, W. C. (1975). Sleep studies on a 90minute day. Electroencephalography and Clinical Neurophysiology, 39, 145-155.

Dement, W. C., Seidel, W., \& Carskadon, M. (1982). Daytime alertness, insomnia, and benzodiazepines. Sleep, 5, S28-S45.

Dudley, R., Huband, P., Hartley, L., \& Brown, K. (1972). The effect of partial sleep loss on some cognitive aspects of the tank commander's tasks. Army Personnel Research Establishment Report 16/72, Farnborough, Hampshire.

GreEnhouse, S. W., \& GeIsSER, S. (1959). On methods in the analysis of profile data. Psychometrika, 24, 95-112.

Hamilton, P., Wilkinson, R. T., \& Edwards, R. S. (1972). A study of four days partial sleep deprivation. In W. P. Colquhoun (Ed.), Aspects of human efficiency (pp. 101-112). London: English Universities Press.

HARTLEY, L. R. (1974). A comparison of continuous and distributed reduced sleep schedules. Quarterly Journal of Experimental Psychology, 26, 8-14.

Haslam, D. R. (1982). Sleep loss, recovery sleep, and military performance. Ergonomics, 25, 163-178.

Haslam, D. R., Allnutt, M. F., Worsley, D. E., Dunn, D., AbrahaM, P., Few, J., Labuc., S., \& LaWRence, D. J. (1977). The effect of continuous operations upon the military performance of the infantryman (Exercise Early Call I). Army Personnel Research Establishment Report 2/77, Farnborough, Hampshire.

HoRNe, J. A. (1978). A review of the biological effects of total sleep deprivation in man. Biological Psychology, 7, 55-102.

HoRNE, J.A. (1981). Sleep deprivation, stress and sleep function. In W. P. Koella (Ed.), Sleep 1980: Proceedings of the Fifth European Congress on Sleep Research (pp. 95-97). Basel: Karger.

Kleitman, N. (1972). Sleep and wakefulness. Chicago: University of Chicago Press.

McNair, D. M., Lorr, M. \& Droppleman, L. F. (1971). Manual for the Profile of Mood States. San Diego: Educational and Industrial Testing Service.

Moses, J. M., Hord, D. J., Lubin, A., Johnson, L. C., \& NaIToH, P. (1975). Dynamics of nap sleep during a 40-hour period. Electroencephalography and Clinical Neurophysiology, 39, 627-633.

Mullaney, D. J., KRIPKe, D. F., \& FleCK, P. (1981). Sleep loss effects on continuous sustained performance (Tech. Rep. No. 1, Contract No. ONR N00014-79-C-0317). Arlington, VA: Office of Naval Research.

NaIroH, P. (1981). Circadian cycles and restorative power of naps. In L. C. Johnson, D. I. Tepas, W. P. Colquhoun, \& M. J. Colligan (Eds.), Biological rhythms, sleep and shiftwork: Advances in sleep research (Vol. 7, pp. 553-580). New York: Spectrum.
Opstad, P. K., Ekanger, M. Nummestad, M., \& RaAbe, N. (1978). Performance, mood and clinical symptoms in men exposed to prolonged, severe physical work and sleep deprivation. Aviation, Space and Environmental Medicine, 49, 1065-1073.

TAUB, J. M. (1979). Effects of habitual variations in napping on psychomotor performance, memory and subjective states. International Journal of Neuroscience, 9, 97-112.

TAub, J. M., \& Berger, R. J. (1973). Performance and mood following variations in the length and timing of sleep. Psychophysiology, 10, 559-570.

TAUB, J. M., \& BERGER, R. J. (1976). The effects of changing the phase and duration of sleep. Journal of Experimental Psychology: Human Perception and Performance, 2, 30-41.

Thorne, D., Genser, S., Sing, H., \& Hegge, F. (1983). Plumbing human performance limits during 72 hours of high task load. In Proceedings of the Twenty-Fourth NATO Defense Research Group Seminar on the Human as a Limiting Element in Military Systems (Vol 1, pp. 17-40). Brussels: NATO.

WEBB, W. B., \& AGNEW, H. W., JR. (1965). Sleep: Effects of a restricted regime. Science, 150, 1745-1747.

WEBB, W. B., \& AGNEW, H. W., JR. (1974). The effects of a chronic limitation of sleep length. Psychophysiology, 11, 265-274.

WEBB, W. B., \& AGNEW, H. W., JR. (1977). Analysis of the sleep stages in sleep-wakefulness regimes of varied length. Psychophysiological Research, 14, 445-450.

Weitzman, E. D., Nogeire, C., Perlow, M., Fukushima, D., Sassin, J., McGregor, P., Gallagher, T. F., \& Hellman, L. (1974). Effects of a prolonged 3-hour sleep-wake cycle on sleep stages, plasma cortisol, growth hormone and body temperature in man. Journal of Clinical Endocrinology, 38, 1018-1030.

Whiting, H. F., \& ENGLISH, H. B. (1925). Fatigue tests and incentives. Journal of Experimental Psychology, 8, 33-49.

Wilkinson, R. T. (1969). Sleep deprivation: Performance tests for partial and selective sleep deprivation. In L. A. Abt \& B. F. Reiss (Eds.), Progress in clinical psychology (Vol. 7, pp. 28-43). New York: Grune \& Stratton.

Wilkinson, R. T., Edwards, R. S., \& Haines, E. (1966). Performance following a night of reduced sleep. Psychonomic Science, 5, 471-472.

WINER, B. J. (1971). Statistical principles in experimental design. New York: McGraw-Hill.

\section{NOTE}

1. The criteria of the Declaration of Helsinki are not applicable to these exercises, which were based on normal military duty and were carried out under military command. 